\title{
Immune Transcripts of the Pacific Oyster, Crassostrea gigas Larvae that Change in Expression as a Result of Bacteria Challenge
}

\author{
Jing Fang \\ Beibu Gulf University \\ Xiaohui Cai \\ Beibu Gulf University \\ Fengyi Mao \\ Zhejiang University \\ Hongyu Li \\ Beibu Gulf University \\ Honglin Chen \\ Beibu Gulf University \\ Minhua Qian \\ Beibu Gulf University \\ Jacob M Hambrook \\ University of Alberta School of Public Health \\ Patrick C Hanington \\ University of Alberta School of Public Health \\ Xinzhong Wu ( $\nabla$ wuxzqinzhou@163.com) \\ Beibu Gulf University
}

\section{Research article}

Keywords: Crassostrea gigas, Bacteria challenge, Transcriptome, Immune genes

Posted Date: May 8th, 2020

DOl: https://doi.org/10.21203/rs.3.rs-23603/v1

License: (c) (i) This work is licensed under a Creative Commons Attribution 4.0 International License.

Read Full License 


\section{Abstract}

Background: Marine molluscs living in intertidal and estuarine areas, such as oysters, face numerous pathogen challenges during their development. Infection from bacteria such as Vibrio alginolyticus, represents a major factor affecting larval development and frequently leads to high mortality of the pacific oyster, Crassostrea gigas. The oyster immune response is known to play an important role in protecting the animal during development by mitigating the consequences of infection.

Results: In this study, we undertook a comprehensive analysis of the immune response of $C$. gigas to $V$. alginolyticus challenge. We sequenced the transcriptome of $C$. gigas at $0,6,12,24,48$ and 72 hours post infection. After RNA-seq, the raw reads are available through the NCBI Sequence Read Archive under accession number PRJNA623063. After filtering, a total of $58.24 \mathrm{~Gb}$ clean reads were produced and assembled using the reference genome of $C$. gigas. The distribution of quality Q30 was higher than $90.88 \%$ for each sample and the GC content ranged from $41.27 \%$ to $42.91 \%$. When compared with sequences in the COG, GO, KEGG, Swiss-Prot, and NR databases, there were 1267, 1112, 2187, 682, 1133 differentially expressed genes annotated at $6,12,24,48,72$ hours post infection respectively. Numerous immune-related genes displayed differential expression that varied over time: toll-like receptors, tripartite motif proteins, Lectin-like factors, scavenger receptors, signaling pathway components such as Myeloid differentiation factor 88 , and stress proteins such as Heat shock $70 \mathrm{kDa}$ protein were all found to be higher in abundance following $V$. alginolyticus challenge compared to control. For analysis, these genes were divided into several categories such as pattern recognition receptors, fibrinogen-like proteins, damage associated molecular patterns, complement factors, etc. These general categories allowed us to generate an immune response profile for $C$. gigas over the first 72 hours of infection. These results indicate that bacterial infection induce a complex pattern of immune gene expression in $C$. gigas larvae.

Conclusion: Our study will facilitate targeted investigation into the function of specific immune factors that may explain the diversity and evolution of invertebrate immune molecules and lead to the development of effective measures to improve the performance of oyster culture.

\section{Background}

The Pacific oyster Crassostrea gigas has a global distribution. Within the intertidal zone, $C$. gigas plays an important ecological role, however, it has also become a key commercial animal in many countries around the world [1]. In recent years, C.gigas farms in China have suffered from a high and unpredictable mortality that was found to be most detrimental during the early developmental stages of the oyster. The primary cause of this mortality has been found to be exposure to the pathogenic bacteria Vibrio alginolyticus [2]. The marine, gram-negative bacterium $V$. alginolyticus is ubiquitous in seawater and seafood all over the world, and is a main pathogen of marine culture animals such as fish, shrimp, and shellfish [3]. Despite the importance of $V$. alginolyticus to marine culture, we know very little about how it leads to mortality in $C$. gigas. In particular, there is a significant gap in our understanding of how the larval oyster responds to challenge by $V$. alginolyticus throughout development [4]. 
The Pacific oyster, $C$. gigas, is an important aquaculture oyster throughout the world, the global production of this species had expanded to 4.38 million tonnes, more than any other species of fish, molluscs or crustacea (FAO, http://www.fao.org/fishery/culturedspecies/Crassostrea_gigas/en). Because of this economic relevance, and the relative ease to culture it in controlled lab conditions, $C$. gigas has emerged as an important model organism for studying bivalve biology. Despite this, our understanding of the immune mechanisms that protect $C$.giga is still largely unknown. Based on our current knowledge, there are only a few studies that focus on advancing our understanding about the oyster immune response against bacterial challenge [5-9]. The genome of $C$. gigas was reported in 2012, highlighting genes involved in apoptosis, environmental stress adaptability and shell formation. The immune system was given specific attention, but how the immune genes changed in expression after bacterial challenge were still unelucidated [10].

Studies that have attempted to characterize the immune capabilities of $C$. gigas following challenge with a pathogen or pathogen-associated molecular pattern (PAMP) have primarily focused on assessing specific factors. For example, Gueguen et al. (2003) investigated transcriptional changes in four immunerelated genes of $C$.gigas following challenge with $V$. anguillarum, $V$. metshnikovii, $V$. tubiashii and $V$. S322 [11]. Tirapé et al. (2007) selected to focus on 18 immune-related genes from C.gigas EST library and analyzed their expression pattern after Vibrio tasmaniansis, V. anguillarum and Micrococcus luteus challenge during oyster ontogenesis [7]. Song et al. (2016) reported some immune-related genes expression change after $V$. splendidus infection at embryonic and larval development stages of the Pacific oyster, such as phagocytosis (Integrin b-1), hematopoiesis (Gata3), immune recognition (C-type lectin 3, TLR4 and Caspase-3), immune elimination (Interleukin 17 - 5, defensin, superoxide dismutase, catalase and heat shock protein 70) and signaling transduction (REL and serine kinase I kinase) [5]. While these studies provide valuable insight into the immune repertoire of $C$. gigas and how it is implemented in the face of infection, it does not provide a comprehensive overview of the organism-wide response.

Profiling the change of abundance of immune-related transcripts following challenge with pathogens or pathogen-associated molecular patterns (PAMPs) provides insight into how the immune response is directed against pathogen insult. Considering that bacterial infection can have serious consequences for the survival of oysters, especially during the larvae stages [6], and that in the past decades, the knowledge of immune processes in adult molluscs has been studied well, however the information in larval stages is scarce. In this study, we sequenced the transcriptome of larval $C$. gigas at $0,6,12,24,48,72$ hours post $V$. alginolyticus exposure by means of Illumina RNA-Seq technology. The general transcriptome was selectively analyzed to identify transcripts that displayed differential expression that varied between exposed and control animals and that also mapped to a putative immune role based on Gene Ontology (GO) searches. Numerous immune-related genes displayed differential expression that varied over time: toll-like receptors (TLRs), tripartite motif proteins (TRIM), Lectin-like factors, scavenger receptors, signaling pathway components such as Myeloid differentiation factor 88 (MyD88), and stress proteins such as Heat shock $70 \mathrm{kDa}$ protein (Hsp70) were all found to be higher in abundance following $V$. alginolyticus challenge compared to control. For analysis, these genes were divided into several categories such as pattern recognition receptors (PRRs), fibrinogen-like proteins (FREPs), damage 
associated molecular patterns (DAMPs), complement factors, etc. These general categories allowed us to generate an immune response profile for $C$. gigas over the first 72 hours of infection. To our knowledge, this is the first study to undertake a comprehensive transcriptome analysis of the immune responses of C.gigas to bacterial challenge. It will facilitate targeted investigation into the function of specific immune factors that may explain the diversity and evolution of invertebrate immune molecules and lead to the development of effective measures to improve the performance of oyster culture.

\section{Results}

\section{Transcriptome sequence assembly}

The raw reads are available through the National Center for Biotechnology Information Sequence Read Archive under accession number PRJNA623063. Quality assessment of the RNA-Seq data indicated that the distribution of quality Q30 was higher than $90.88 \%$ for each sample and the GC content ranged from 41.27-42.91\%. After filtering, 69.13-73.40\% clean reads were successfully matched to the C.gigas genome by the TopHat2 software (Table 1 ). These results demonstrate that the sequencing quality was quite good, suggesting that the later transcriptome analysis results are reliable. 
Table 1

Statistical analysis of transcriptome sequencing data

\begin{tabular}{|c|c|c|c|c|c|c|}
\hline Samples & $\begin{array}{l}\text { Total } \\
\text { reads }\end{array}$ & Clean bases & $\begin{array}{l}\text { GC } \\
\text { content }\end{array}$ & $\% \geq Q 30$ & $\begin{array}{l}\text { Mapped } \\
\text { Reads }\end{array}$ & $\begin{array}{l}\text { Uniq Mapped } \\
\text { Reads }\end{array}$ \\
\hline \multirow[t]{2}{*}{$\mathrm{AO}$} & $42,488,110$ & $5,351,710,454$ & $41.75 \%$ & $91.46 \%$ & $31,188,582$ & $19,782,843$ \\
\hline & & & & & $(73.40 \%)$ & $(46.56 \%)$ \\
\hline \multirow[t]{2}{*}{ BO } & $38,473,752$ & $4,846,637,071$ & $42.04 \%$ & $91.14 \%$ & $27,677,607$ & $18,261,039$ \\
\hline & & & & & (71.94\%) & $(47.46 \%)$ \\
\hline \multirow[t]{2}{*}{ A6 } & $40,707,324$ & $5,128,064,912$ & $41.90 \%$ & $91.30 \%$ & $29,169,443$ & $19,418,802$ \\
\hline & & & & & (71.66\%) & $(47.70 \%)$ \\
\hline \multirow[t]{2}{*}{ B6 } & $34,522,894$ & $4,349,075,066$ & $42.18 \%$ & $90.99 \%$ & $24,943,918$ & $15,868,534$ \\
\hline & & & & & $(72.25 \%)$ & $(45.97 \%)$ \\
\hline \multirow[t]{2}{*}{ A12 } & $32,554,310$ & $4,100,687,702$ & $41.90 \%$ & $91.10 \%$ & $23,655,300$ & $14,576,967$ \\
\hline & & & & & (72.66\%) & (44.78\%) \\
\hline \multirow[t]{2}{*}{ B12 } & $33,339,774$ & $4,199,859,397$ & $42.09 \%$ & $90.88 \%$ & $23,989,252$ & $15,443,427$ \\
\hline & & & & & (71.95\%) & $(46.32 \%)$ \\
\hline \multirow[t]{2}{*}{ A24 } & $33,757,068$ & $4,252,398,874$ & $42.91 \%$ & $91.98 \%$ & $23,601,167$ & $17,022,091$ \\
\hline & & & & & $(69.91 \%)$ & $(50.43 \%)$ \\
\hline \multirow[t]{2}{*}{ B24 } & $33,931,500$ & $4,274,327,515$ & $42.58 \%$ & $91.11 \%$ & $23,457,081$ & $17,177,554$ \\
\hline & & & & & $(69.13 \%)$ & $(50.62 \%)$ \\
\hline \multirow[t]{2}{*}{ A48 } & $44,693,968$ & $5,630,071,580$ & $41.53 \%$ & $91.23 \%$ & $32,537,843$ & $18,410,125$ \\
\hline & & & & & (72.80\%) & $(41.19 \%)$ \\
\hline \multirow[t]{2}{*}{ B48 } & $45,165,578$ & $5,689,621,662$ & $41.27 \%$ & $91.08 \%$ & $33,026,475$ & $19,172,544$ \\
\hline & & & & & $(73.12 \%)$ & $(42.45 \%)$ \\
\hline \multirow[t]{2}{*}{ A72 } & $44,709,090$ & $5,631,977,422$ & $42.29 \%$ & $91.02 \%$ & $31,729,863$ & $21,427,551$ \\
\hline & & & & & (70.97\%) & $(47.93 \%)$ \\
\hline \multirow[t]{2}{*}{ B72 } & $37,974,962$ & $4,783,468,880$ & $42.07 \%$ & $91.10 \%$ & $27,029,298$ & $17,495,218$ \\
\hline & & & & & (71.18\%) & $(46.07 \%)$ \\
\hline
\end{tabular}




\section{Functional annotation and classification of the differentially expressed genes (DEGs) between experimental and control groups}

Total, up- and down-regulated DEGs were detected between the experimental and control group at different time points after bacterial infection (see Additional file 1). Compared with sequences in the Cluster of Orthologous Groups of proteins (COG), GO, Kyoto Encyclopedia of Genes and Genomes (KEGG), Swiss-Prot, and NCBI non-redundant protein sequences (NR) databases, there were 1267, 1112, $2187,682,1133$ DEGs annotated at $6,12,24,48,72$ hours post infection (hpi) respectively (Table 2). The number of total DEGs $(2,187)$ was the highest at $24 \mathrm{hpi}$, of which 1745 DEGs were up-regulated and 442 were down-regulated. All the DEGs at each time point were mapped to a variety of GO annotations and three main functional classifications were determined (Fig. 1 and see Additional file 2): cellular component, molecular function, and biological process. Based on the $\mathrm{GO}$ analysis results, most immunerelated genes were enriched in the category of biological process. Pathway enrichment analysis identified significantly enriched immune pathways in DEGs and showed that specific immune pathways were significantly altered following $V$. alginolyticus challenge (Fig. 2). KEGG pathway analysis suggested that these DEGs could be assigned to specific immune-related pathways such as Toll-like receptor signaling pathway, NOD-like receptor signaling pathway, mitogen-activated protein kinases (MAPK) signaling pathway and Apoptosis were enriched in these signaling pathways (Fig. 3 and see Additional file 3 ).

Table 2

Table Statistical analysis of differentially expressed genes

\begin{tabular}{|lllllll|}
\hline DGE Set & Annotated & COG & GO & KEGG & Swiss-Prot & NR \\
\hline C vs T1 & 1,267 & 277 & 512 & 262 & 716 & 1,266 \\
\hline C vs T2 & 1,112 & 312 & 500 & 285 & 647 & 1,111 \\
\hline C vs T3 & 2,187 & 503 & 875 & 456 & 1,260 & 2,186 \\
\hline C vs T4 & 682 & 150 & 289 & 135 & 392 & 681 \\
\hline C vs T5 & 1,133 & 261 & 452 & 226 & 656 & 1,133 \\
\hline
\end{tabular}

Note: T1, T2, T3, T4, T5 mean the time point ( 6 h, 12 h, 24 h, 48 h, 72 h) of oyster larvae post bacterial challenge.

\section{The significantly up-regulated expressed immune-related genes analysis caused by V. alginolyticus}

According to the analysis of GO terms and KEGG pathways, we selected the up-regulated immune-related genes with a strict threshold criterion ( $\log _{2}$ Fold Change $(F C) \geq 1.5$ and FDR $<0.01$ ) (see Additional file 4). Our analyses indicate that 12 immune-related transcripts were increased in abundance at each time point after $V$. alginolyticus challenge (Fig. 4). Various well-known immune-related genes such as TLRs, 
peptidoglycan-recognition protein, heat shock protein, complement C1q protein, interleukin 17-like protein, and myeloid differentiation primary response protein MyD88, were identified separately and divided into general categories based on their function during an immune response. These categories included; TLRs, PRRs, DAMPs, Complement, Immune effector, Cytokines, Tripartite motif-containing proteins and Immune signaling pathway (see Additional file 5).

\section{Pattern Recognition Receptors}

PRRs can directly recognize and bind conserved PAMPs on the surface of invaders and play an important role in the innate immune defense response. Numerous PRRs were found in higher abundance in $C$.gigas transcriptome after $V$. alginolyticus infection compared to controls. At nearly every time point post challenge various PRRs were were up-regulated. A majority of PRRs genes exhibited higher expression levels from $6 \mathrm{hpi}$ to $24 \mathrm{hpi}$ and the expression of them reduced rapidly at $48 \mathrm{~h}$ post-stimulation, some of them then were increased at $72 \mathrm{hpi}$. Scavenger receptor class $\mathrm{F}$ member 2 , scavenger receptor cysteinerich domain superfamily protein (precursor), C-type receptor 2 and macrophage mannose receptor 1 were down-regulated (see Additional file 5: Table S1).

It is well known that TLRs as pattern recognition receptors play a vital role in initiating innate immune responses against pathogens challenge. A variety of TLRs expression were obviously up-regulated after $V$. alginolyticus infection (see Additional file 5: Table S2). The abundance of numerous $C$. gigas TLRs genes increased steadily between $6 \mathrm{hpi}-24 \mathrm{hpi}$, then dropped gradually at $48 \mathrm{hpi}-72 \mathrm{hpi}$ and some TLRs genes were raised again at $72 \mathrm{hpi}$.

\section{Damage associated molecular patterns}

DAMPs are endogenous danger signals that can activate immune cells and originate from damaged or necrotic tissues. A common group of proteins that are often categorized as DAMPs are the heat shock proteins (HSPs), which have a vital role in protecting cells against environmental stresses such as heat shock, heavy metal exposure, bacterial infection or almost any sudden changes inducing protein damage in the cellular environment [12]. In our study, we found that the transcriptome abundance of Hsp70 12A was notably increased by bacterial infection compared to controls at time points $6,12,24,48$, and $72 \mathrm{~h}$ respectively. The expression level of Hsp70 12A steadily declined at $12 \mathrm{hpi}$ and increased at $24 \mathrm{hpi}$, then decreased at $48 \mathrm{hpi}$ and raised at $72 \mathrm{hpi}$ (see Additional file 5: Table S3). We also found that abundance of Hsp 68 decreased within $12 \mathrm{~h}$ against $V$. alginolyticus challenge, then the abundance of this transcript increased by bacterial infection compared to controls among $24 \mathrm{hpi}-72 \mathrm{hpi}$ (see Additional file 5: Table S3).

\section{Complement}

The complement system plays a key role in innate immunity and is widely involved in physiological and pathological processes, such as phagocytosis, cytolysis, inflammation, solubilization of immune complexes, clearance of apoptotic cells and promotion of humoral immune responses [13-15]. In this study, four transcripts that reflect Complement component receptor 1-like protein, complement C1q tumor 
necrosis factor-related protein 3, complement C1q-like protein 4 and complement C1q-like protein 3, were identified in the $C$.gigas transcriptome after bacterial infection. Abundance of the complement component receptor 1-like protein (CR1L) transcript increased gradually and reached a maximum level at $48 \mathrm{~h}$ post-stimulation, then declined progressively and down regulated straightly at $72 \mathrm{hpi}$ (see Additional file 5: Table S4). The abundance of other three complements increased at $6 \mathrm{hpi}$ and the decreased level appeared at $48 \mathrm{hpi}$, and then sharp raised up the maximum level at $72 \mathrm{hpi}$.

\section{Tripartite motif-containing (TRIM) proteins}

TRIM proteins have been implicated in multiple cellular functions including apoptosis, immune signaling, antiviral activity, cell proliferation, differentiation and oncogenesis. TRIM proteins including 23 TRIM2, 2 TRIM3, TRIM75 and E3 ubiquitin-protein ligase displayed increased expression post bacterial infection in our study (see Additional file 5: Table S5). Five TRIM2 were found to be most abundant at $6 \mathrm{hpi}$ after which, the abundance dropped immediately at the other five time points, seven TRIM2 and TRIM75 were sharp reached the maximum level at $72 \mathrm{hpi}$, TRIM3 were raised up the highest level at $12 \mathrm{hpi}$ and then subsequently decreased progressively.

\section{Cytokines}

Cytokines are produced and secreted by cells in response to various stimulation and play vital roles in the host defense response to pathogens by performing myriad immune-relevant roles. In this study, we found three IL17 were notable up-regulated at different time points after bacterial infection (see Additional file 5: Table S6). The transcriptome expression of two IL 17 steadily declined at $12 \mathrm{hpi}$ and increased at $24 \mathrm{hpi}$, then dropped immediately at $48 \mathrm{hpi}$ and raised at $72 \mathrm{hpi}$, the minimum level of IL17 appeared at $48 \mathrm{hpi}$.

\section{Immune signaling pathway}

MyD88 is a key adapter molecule in TLR signaling pathway and played an important role in transmitting upstream information and pathogen defense. Once MyD88 has associated with the receptor TIR domain, IL-1 receptor-associated kinase 4 (IRAK4) is recruited to the receptor complex, subsequently interact with TNF receptor-associated factor 6 (TRAF 6 ) to activate downstream signals, such as nuclear factor-KB (NF-KB) and MAPK, inducing the production of inflammatory cytokines and/or type I interferon to eliminate invading pathogens.

In this study, we found the expression of TLR, MyD88, TRAF family protein and IRAK4 were significantly up-regulated following bacterial challenge (see Additional file 5: Table S7). Five MyD88 genes expression were significantly increased at each time point post infection. Among these time points, MyD88 were expressed the highest level at $6 \mathrm{hpi}$, then dropped immediately to a minimum at $48 \mathrm{hpi}$ and subsequently increased progressively. Two TRAF family protein were notable up-regulated at different time points post bacterial infection and one TRAF family protein was found to be most abundant at $6 \mathrm{hpi}$ after which, the abundance declined gradually at the other five time points. Abundance of two IRAK4 transcript reached a maximum level at $6 \mathrm{~h}$ post-stimulation, and then subsequently decreased progressively. 


\section{Validation of genes expression profiles by Quantitative Real- time PCR (qRT-PCR)}

To validate the transcriptome expression profiles, ten representative up-regulation immune-related DEGs were selected for qRT-PCR analysis at $6 \mathrm{~h}, 12 \mathrm{~h}, 24 \mathrm{~h}, 48 \mathrm{~h}$ and $72 \mathrm{~h}$ after treatment with the elongation factor 1 a (EF1-a) gene as internal control (Fig. 5). The overall trend of qRT-PCR-based expression patterns of ten selected genes Hsp70, Peptidoglycan-recognition protein SC2 (PRR), TLR6, IL17, Complement C1q-like protein 4 (C1q4), MyD88, Serine protease inhibitor dipetalogastin (SPI), Alternative oxidase, mitochondrial (AOM), TNF receptor-associated factor family protein (TRAFP) and Fibrinogen C domain-containing protein $1(\mathrm{FC} 1)$ were similar to those obtained by transcriptome analysis, indicating that the reliability of the expression profiling determined by RNA-seq was reliable and accurate, although the expression fold changes of most genes measured by qRT-PCR were more than those from transcriptome analysis.

\section{Discussion}

It is well established that marine molluscs possess an effective and robust immune response that protects them against infection [16]. To date, however, most of the studies that have characterized the immune responses of these animals have focused on adult individuals, while the immune response in juveniles/larvae has received less attention. For oysters and other bivalves, the developmental stages from trochophore to larvae are indispensable as calcified shells will be formed and the immune system becomes mature during this developmental stage [17]. During this developmental period, there can be lethal consequences should any infectious agent impact the developing organism. Before any functional differences in the immunological capabilities between larval and adult organisms can be assessed, it is important to establish a baseline of those immune factors that are likely relevant during the larval stage. In this study, the expression of immune-related genes in the larvae of $C$. gigas after challenge by the bacterial pathogen $V$. alginolyticus was studied to demonstrate the immune-specific transcriptome during ontogenesis.

\section{Pattern recognition receptors}

PRRs are an important part of the innate immune response. This general classification of immune receptors is defined by their ability to directly recognize different PAMPs such as lipopolyssacharide (LPS) and peptidoglycan (PGN) from bacteria, $\beta$-1,3-glucan from fungi, or double-stranded RNA from viruses [18]. To date, several PPRs (e.g TLRs, fibrinogen-related proteins, LPS-binding proteins, peptidoglycan recognition proteins and scavenger receptors) have been reported from invertebrates, including $C$. gigas [19-21]. As reported here, numerous PPRs have been detected as presenting increased abundance in the $C$. gigas transcriptome following bacterial challenge. $C$. gigas TLRs, peptidoglycan recognition proteins (PGRPs), scavenger receptors (SRs), fibrinogen-like proteins (FREPs), calciumdependent (C-type) mannose receptor, macrophage mannose receptor (MMR), lectins, C-type receptor, 
protein toll, collectin-12 and hemolymph lipopolysaccharide-binding protein (LPS-BP) were found in higher abundance in challenged groups compared to controls (see Additional file 5: Table S1). Besides TLRs, which are discussed in detail below, other PRRs found in this transcriptome study have also been identified in C. gigas [18], Eriocheir sinensis [22], the Sydney Rock Oyster Saccostrea glomerata [23], Limulus polyphemus [24] from PGRPs, SRs, FREPs, C-type mannose receptor, MMR, lectins, and protein toll to collectin-12 and LPS-BP. PGRPs which can recognize peptidoglycan and peptidoglycan-containing bacteria play an indispensable role in innate immunity for invertebrates and vertebrates, due to its outstanding ability in detecting and eliminating invasive bacteria. Yang et al. [25] reported the upregulated expression of PGRPs in Zhikong scallop $C$. farreri after bacterial challenge and the recombinant protein exhibited strong agglutination activity to the Gram-positive bacteria Micrococcus luteus and Bacillus subtilis. Similar to this result, we also found the transcription expression of PGRPs were obviously up-regulated after $V$. alginolyticus infection and a clearly time-dependent expression pattern of PGRPs was observed. It is conceivable that the C.gigas PGRPs found in this study could serve not only recognize bacterial invasion, but also play a role in eliminating the pathogen.

Adema et al. and Li et al. found that a role for invertebrate FREPs in recognition of parasite-derived molecules and FREPs are proteins with at least a fibrinogen-like (FBG) domain, they are widespread in Mollusca [26-28], and play curial roles in the innate immune response as PRRs. In this study, we found the gene expression of FREPs were up-regulated significantly post bacterial challenge. Consistent with our study, up-regulation of FREPs were also reported in snail B. glabrata [28-30], amphioxus Branchiostoma belcheri [31], mosquito Armigeres subalbatus [32], C. gigas [20], and Anopheles gambiae $[33,34]$. It is inferred that the FREPs found in this study can play important roles as PRRs in the innate immune response and inhibit infection from pathogens.

SRs are a group of heterogeneous molecules on the surface of phagocytes and play an important role in innate immunity, which can recognize and mediate engulfment of a variety of pathogenic substances to eliminate the invading pathogens. An up-regulation SR induced by LPS, PGN and $\beta$-glucan was observed in the scallop $C$. farreri and SR recombinant protein can interact with LPS, PGN and the fungal particles mannan and zymosan in the presence of $\mathrm{Ca}^{2+}[21]$. In our study, we also find a related SR up-regulated under similar circumstances. These results show that PRRs playing as detecting PAMPs in invertebrates as they are in mammalian. C-type lectin superfamily have been reported to play a potential role in the activation of complement system in C.gigas [35] and mediate pathogen recognition and cellular adhesion in $C$. farreri [36]. C-type lectins, collectins and macrophage mannose receptor formed this family and it was investigated that they were also associated with the cell membrane and phagocytosis [37]. For oysters with only innate immune system to defend various pathogen infection, a series of PRRs might give $C$.gigas an ability against invading pathogens.

\section{Toll-like receptors}

Tolls or TLRs play an indispensable role in initiating innate immune responses against pathogens challenge. Since the first description of Toll and its role in the immune response against fungal infection in Drosophila melanogaster [38], a large number of TLRs have been reported and functionally 
characterized in various species. As an ancient family of evolutionary conserved PRRs, TLRs, which are found in many species including mammals, flies, crustaceans and molluscs, are playing as crucial roles in immune system [23]. They play a key role in early host defense against invading pathogens by recognizing conserved PAMPs and activating downstream signaling pathways which can induce the production of inflammatory cytokines and/or type I interferon to clear invading pathogens. Along with the TLRs identified in this study, TLRs have also been reported in C.gigas genome [10] and other molluscs such as the pearl oyster Pinctada fucata martensii [39], Hyriopsis cumingii [40]. Wang et al. reported that TLR6, identified in C.gigas, could function as an important pattern recognition receptor in the early detection and response against invading gram-negative bacteria $V$. anguillarum, $V$. splendidus, and grampositive bacteria Staphylococci aureus, Micrococcus luteus, and fungi Pichia pastoris in oysters [41]. The Tolls identified from a marine crab, Portunus trituberculatus have been reported to participate in the host defense against $V$. alginolyticus, Candida lusitaniae and white spot syndrome virus [42]. A study indicated that the expression of a Toll from E. sinensis was significantly upregulated after LPS, PGN and zymosan (GLU) challenge [43]. Similar to above studies, we have also found some TLRs/Tolls expression upregulation from our analysis of the $C$.gigas transcriptome, including transcripts that represent protein tolls, TLR6, TLR13, TLR1 TLR2 and TLR4. Given the consistent increase in expression, it could be inferred that TLRs likely play an essential role in bacteria recognition and subsequent activation of the innate immunity.

It is well known that TLRs play an indispensable role in recognition of invaders and their stimulation by PAMP ligands such as LPS and DAMP ligands such as Hsp70 induces a TLR signaling pathway which plays a vital role in the immune defense against pathogen infection by activating the diverse downstream reaction including anti-oxidant, anti-bacteria and apoptosis $[44,45]$. MyD88 is a widespread and important adaptor for TLR/IL-1R family, and primarily recruited to activate TLR after the recognition of PAMPs/DAMPs by TLRs. Once MyD88 has associated with the receptor TIR domain, IRAK4 is recruited to the receptor complex, subsequently interact with TRAF6 to activate downstream signals, such as NF-KB and MAPK, inducing the production of inflammatory cytokines and/or type I interferon to eliminate invading pathogens.

In the present study, we also found the expression of TLR, MyD88, TRAF family protein and IRAK4 were significantly up-regulated following bacterial challenge, but NF-KB has not been found in the $C$. gigas transcriptome. Similar to our results, Jiao et al. showed an up-regulated expression of MyD88 post stimulation by LPS in P. fucata martensii [46], and these results were echoed by Wang et al. that reported both MyD88 and TRAF6 were up-regulated after LPS stimulation [47]. Tang et al. found IRAK4 could inhibit MyD88-induced NF-KB activation in Pacific oyster with Oyster herpesvirus-1 microvariant (OsHV-1 mvar), $V$. alginolyticus, and poly I:C challenge [48]. Considering the above results and that our C.gigas transcriptome analysis contains multiple TLR and MyD88 transcripts that demonstrate an increase in abundance following bacterial challenge, it was inferred that a MyD88-dependent TLR signaling pathway also existed in C.gigas larvae and TLRs and the adaptor protein MyD88 respond to a range of pathogens, indicating they play an important role in the innate immunity of oyster. 


\section{Damage associated molecular patterns}

DAMPs are endogenous danger signals that can activate immune cells and originate from damaged or necrotic tissues. To date, various DAMPs such as HSPs and high-mobility group box 1(HMGB1) have been identified and characterized in invertebrates and vertebrates $[49,50]$. A common group of proteins that are often categorized as DAMPs are the HSPs. As stress proteins, HSPs are ubiquitous and evolutionarily conserved, known to exist in all living organisms [51-53]. They play indispensable roles in protecting cells against environmental stresses such as heat shock, heavy metal exposure, bacterial infection or almost any sudden changes inducing protein damage in the cellular environment [12]. According to their molecular weight, these proteins have been classified into several families, such as HSP90 (85-90 kDa), HSP70 (68-73 kDa), HSP60, HSP47, and low molecular mass HSPs (16-24 kDa) [54]. Among these proteins, HSP70s have been studied extensively and are most responsible for intracellular chaperone and extracellular immunoregulatory functions as DAMPs [50]. Recently, the role of HSP70s in activating innate immunity and participating in host response to bacteria infection have been reported in mollusks, such as the up-regulation of HSP70 expression in Pinctada martensii against $V$. alginolyticus, the increased expression of HSP70 in Mytilus galloprovincialis by $V$. anguillarum stimuli, the significant expression of HSP70 in Mytilus coruscus affected by $V$. alginolyticus and $V$. harveyi. [50, $53,55]$. Song et al. showed that HSP70 would provide cytoprotection in the $C$. gigas larvae after $V$. splendidus challenge [5]. In this study, we found HSP-70 kDa and HSP-68 kDa expression were increased in $C$.gigas after $V$. alginolyticus challenge and a clearly time-dependent expression pattern of HSP70 was observed. The expression of the HSP70 gene increased at $6 \mathrm{hpi}$ and the maximum level appeared at 24 hpi, and then dropped gradually. Consistent with our study, HSP70 expression up-regulated after the bacteria challenge were also reported in other mollusks, such as Sepiella maindroni [12], P. martensii [50], Laternula elliptica [54], Mytilus coruscus [55], P. fucata [56]. Our results suggested that HSP70 might be involved in oyster response to pathogenic infection and the up-regulated mRNA expression of HSP70 following infection response indicated that the HSP70 might play an important role in oyster immune response.

\section{Complement}

The complement system plays a key role in innate immunity against infection and is widely involved in physiological and pathological processes. The functions of the complement system include phagocytosis, cytolysis, inflammation, solubilization of immune complexes, clearance of apoptotic cells and promotion of humoral immune responses [13-15].

There are four types of protein in the complement system, including inherent components, regulatory molecules, complement receptors and specific protein fragments that can be activated [57]. Complement components such as $\mathrm{C} 1 \mathrm{q}$, mannose-binding lectin and ficolin are PRRs that function as recognizing potential pathogens during immune responses and activating different complement pathways in vertebrates [58]. The key component of the classical complement pathway C1q involved in widespread immunological processes such as apoptotic cells elimination, bacteria and retrovirus recognition, cell 
adhesion and cell growth modulation provides a major connection between innate and acquired immunity [59].

Although the complement system has been well studied in mammals, little is known about complement components in invertebrates. With the first identification of a complement homolog found in the sea urchin in 1996 [60]. The recognition molecules and associated serine proteases, ficolins, MBL-associated serine proteases (MASPs), C1q1, CaC1q2, $\mathrm{C} 3$ and C2/Complement factor $\mathrm{B}$ (Bf) and C1q-domain containing protein have been recently reported in invertebrates [61-66]. In innate immunity, C1q-domain containing proteins can be considered as specialized PRPs because they have the ability to bind pathogens directly through PAMPs and to trigger phagocytosis [67]. A series of the complement related recognition molecules may be induced when foreign microorganisms invade or pathogen-related carbohydrate detection occurs in invertebrate animals. In present study, we used bacteria $V$. alginolyticus to infect the oyster larvae, and then analysed the transcriptome data at different time points. The result showed that the complement component expression was up-regulated after pathogen challenge. Similar to our results, the $\mathrm{C} 1 \mathrm{q}$ domain-containing transcripts up-regulation expression has been reported in mussel, abalone and clam hemocytes against Gram-positive, Gram-negative bacteria and cell wall components (LPS, glucan and peptidoglycan) [68-71]. Interestingly, our study found that abundance of CR1L transcript increased gradually and reached a maximum level at $48 \mathrm{~h}$ post-stimulation, then declined progressively and down regulated straightly at $72 \mathrm{hpi}$ (see Additional file 5: Table S4). It was inferred that the complement system of the oyster larvae could be activated by $V$. alginolyticus to defense bacteria within $48 \mathrm{~h}$ post-stimulation, then the complement system was inhibited, which would suppress the oyster immune response to pathogen challenge. Based on the result above, it could be speculated that the complement played an important role in oyster immune response.

\section{Tripartite motif-containing proteins}

TRIM family consist of more than 70 members of proteins, which are characterized by the presence of three different types of domains: RING finger (R) domain, B-box (B) and a coiled coil (CC) domain. The R domain of many TRIM proteins has been reported to function as E3 ubiquitin ligases by binding to both ubiquitin E2-conjugating enzymes and target proteins to facilitate the selective ubiquitination of the target, whereas the B and $\mathrm{CC}$ domains may be involved in protein interactions and homo/heterodimerization [72]. E3 ubiquitin ligases play as indispensable roles during ubiquitation process and are involved in the regulation of both innate and adaptive immune response [73, 74]. Nabika et al. found that the tumor necrosis factor-a (TNFa) was increased by ubiquitin and lipopolysaccharide synergistically in the murine macrophage cell line RAW 264 , related to the modulatory mechanisms of the immune response [75].

To date, many TRIM proteins have been identified and studied well in mammals [76, 77]. TRIM proteins have been implicated in multiple cellular functions including apoptosis, immune signaling, antiviral activity, cell proliferation, differentiation and oncogenesis. Recent studies have shown that many members of the TRIM superfamily are expressed in response to interferons (IFNs) and are involved in a broad range of biological processes that are associated with innate immunity $[78,79]$. Members of TRIM 
family of E3 ligases are reported as important regulators of innate immunity, such as TLR signaling pathway were regulated by TRIM proteins $[80,81]$.

However, the knowledge about TRIM proteins in mollusks is still limited. Rosani et al. reported that TRIM2 was expressed after ostreid herpesvirus 1-positive challenge in C.gigas [82]. Song et al. found that TRIM3 had the ability to suppress cell proliferation by inactivating p38 signaling pathway and play as a role of tumor inhibitor in cervical cancer [83]. In this study, we identified TRIM proteins (e.g TRIM2, TRIM3 and TRIM75) and E3 ubiquitin-protein ligase as being up-regulated expression after bacterial challenge. Similar to our results, E3 ubiquitin-protein ligase was up-regulated expression in the Pacific oyster after LPS challenge and function as a regulator of immune response against bacterial challenge [84]. Seo et al. reported the ubiquitin was purified from the gill of C.gigas and identified as antimicrobial [85]. Wu et al. found an Rbx1 which belonged to the RING-finger family of Ubiquitin ligase E3 involved in the immune response of abalone Haliotis diversicolor supertexta [86]. According to these above results, we can infer that TRIM protein obtained in the present study might be involved in oyster response to pathogenic infection.

\section{Cytokines}

Cytokines are small proteins including interleukins, IFNs, colony-stimulating factors (CSFs), and TNFs, which are produced and secreted by cells in response to various stimuli. They play vital roles in the host defense response to pathogens by performing myriad immune-relevant roles. [87].

Few of the hallmark cytokines known from mammalian immune studies possess direct ortholog in invertebrates, however, conserved protein domains allow for invertebrate studies to target appealing candidates for functional evaluations. One cytokine that has been shown to be consistent between vertebrates and invertebrates is IL-17, which was significantly up-regulated in the $C$. gigas transcriptome after bacterial challenge. Rouvier et al. first reported that IL-17 as cytolytic T-lymphocyte (CTL)-associated antigen 8, is a T-cell factor with proinflammatory activity [88]. It is well known that IL-17 is an important member of the proinflammatory cytokine family and plays an indispensable role in the eliminating of extracellular bacteria [89]. IL17 also can activate NF-KB and MAPK signal pathways, then induce other cytokines secretion and immune cells migration, further trigger the inflammatory response [87, 90]. IL-17 genes have also been identified in mollusks such as the pearl oyster $P$. fucata [91], the triangle-shell pearl mussel, H. cumingii [93], the Pacific oyster C.gigas [87].

Similar to our results, Li et al. showed that five IL-17 genes identified from the Pacific oyster genome were significantly up-regulated in hemocytes challenged with PAMPs including LPS, heat-killed $V$. alginolyticus and PGN [87]. Wu et al. and Roberts et al. reported the IL17 gene expression in hemocytes of oysters was increased after challenges of bacteria and could activate transcription factors such as NF-KB, which suggested that IL 17-5 acted as an inflammatory cytokine transmitting signals, and play crucial roles in immune recognition and bacteria elimination $[93,94]$. An IL-17 in pearl oyster $P$. fucata has been reported that it was involved in the immune response to LPS and poly $(\mathrm{I}: \mathrm{C})$ stimulation, participated in and activated NF-KB signal pathway in mammalian cells [95]. Based on these above results, it is inferred that 
the IL-17 found in this study can play important roles in the innate immune response and inhibit infection from pathogens.

\section{Conclusions}

The transcriptome of $C$. gigas larvae at $0,6,12,24,48,72$ hours post $V$. alginolyticus exposure was sequenced by means of Illumina RNA-Seq technology. This is the first study to undertake a comprehensive transcriptome analysis of the immune responses of $C$. gigas to bacterial challenge. Numerous immune-related genes displayed differential expression that varied over time: toll-like receptors, tripartite motif proteins, Lectin-like factors, scavenger receptors, signaling pathway components such as MyD88, and stress proteins such as Hsp70 were all found to be higher in abundance following $V$. alginolyticus challenge compared to control. These genes were divided into several categories such as PRRs, FREPs, DAMPs, complement factors, etc. These general categories allowed us to generate an immune response profile for $C$. gigas over the first 72 hours of infection. These results will facilitate targeted investigation into the function of specific immune factors that may explain the diversity and evolution of invertebrate immune molecules and lead to the development of effective measures to improve the performance of oyster culture.

\section{Methods}

\section{Oyster larvae and bacteria treatment}

Adult individuals of oyster $C$. gigas were collected from a farm in Yantai, Shandong Province, China, and acclimatized in laboratory for over one week before subsequent experiments. Sperms and eggs were scratched from gonads of male and female oysters with toothpicks. The fertilization was obtained by mixing sperms and eggs, and then the fertilized embryos were cultured in aerated seawater at $26^{\circ} \mathrm{C}$.

D-hinged larvae were obtained using 300 mesh and challenged by the final concentration of $6 \times 10^{8} \mathrm{CFU}$ of $V$. alginolyticus. Larvae without any treatment were designated as the control group. At the beginning of the bacterial challenge experiment, the samples were washed two times using filtered seawater and DEPC respectively at 1, $200 \mathrm{rpm}$. Then adding $500 \mu \mathrm{L}$ of TRIzol Reagent (Invitrogen, USA) and stored at $-80^{\circ} \mathrm{C}$ for later use. After bacterial challenge, the tissues were obtained by above methods at the following time points: 6 hpi, $12 \mathrm{hpi}, 24 \mathrm{hpi}, 48 \mathrm{hpi}$, and $72 \mathrm{hpi}$.

\section{RNA extraction, cDNA library construction and illumina sequencing}

Total RNA was separately isolated from the six samples using the TRIzol Reagent (Invitrogen, USA) according to the manufacturer's instructions. cDNA library construction and RNA-Seq were performed at Beijing BioMarker Technologies (Beijing, China) in accordance with the institute's protocols. Briefly, RNA degradation and contamination was firstly monitored on $1 \%$ agarose gels. RNA purity was quantified by by a NanoPhotometer spectrophotometer (IMPLEN, CA, USA), RNA integrity was then checked using the 
Agilent Bioanalyzer 2100 (Agilent Technologies, CA, USA), and RNA concentration was further measured by the Qubit RNA Assay Kit in a Qubit 2.0 Flurometer (Life Technologies, CA, USA). Sequencing libraries generated using the NEBNext UltraTM RNA Library Prep Kit for Illumina (NEB, USA) following the manufacturer's instructions were briefly described here. mRNA was purified from total RNA with oligo (dT) magnetic beads and the fragmentation was randomly carried out by treatment with divalent cations under elevated temperature in a fragmentation buffer. Then, the cleaved RNA fragments were transcribed into first strand cDNA using a random hexamer primer and M-MuLV Reverse (RNase H). Second strand cDNA was subsequently synthesized by DNA polymerase I and RNase H. NEBNext Adaptor was added to ligate to the end-repaired, dA-tailed DNA to prepare for hybridization, then adaptor-ligated fragments were purified with the AMPure XP system (Beckman Coulter, Beverly, USA). After PCR amplification, DNA fragments in the range of 200 to $250 \mathrm{bp}$ were obtained for the following procedures. Finally, the libraries were sequenced on an Illumina HiSeq 2500 platform and 125 bp paired-end reads were generated.

\section{RNA-seq data analysis}

For ensuring the accuracy of subsequent analysis, Raw data generated from Illumina sequencing were preprocessed to remove the low-quality sequence and adaptor sequences reads. Raw sequences were transformed into clean reads after data processing. These clean reads were then mapped to the reference genome (C. gigas genome) sequence using Tophat2 tools [96]. Only reads with a perfect match or one mismatch were further analyzed and annotated based on the reference genome. Cufflinks was used to assemble the mapped reads and then the reads were compared with the annotation of the reference genome to acquire new transcripts and fragments per kilobase of transcript (FPKM) value was used as an indicator to measure the level of gene expression [97]. The obtained unigenes were used for a BLAST search and functionally annotated against the NR, Swiss-Prot, GO, COG, KOG (Eukaryotic Orthologous Groups), KEGG and Pfam databases.

\section{The differentially expressed transcripts analysis}

DESeq software [98] applied to experiments with biological repetition was then used to determine the differential gene expression of every 2 groups of samples with a threshold criterion of $\log _{2} F C \geq 1$ and FDR $<0.01$, for up-regulated and down-regulated transcripts. GO analysis was performed to determine the biological implications of the differentially expressed genes. For enrichment analysis, all differentially expressed genes were mapped to terms in GO and KEGG databases, and then we searched for significantly $(P \leq 0.05)$ enriched $G O$ and KEGG terms in DEGs compared with the overall transcriptome.

\section{Validation using quantitative real-time PCR (qRT-PCR)}

To confirm our Illumina sequencing data, ten representative genes including Hsp70, PRR, TLR6, IL17, C1q4, MyD88, SPI, AOM, TRAFP and FC1 were selected for qRT-PCR. Gene-specific primers of all the genes above were designed using Primer 3.0 and EF1-a gene was chosen as an internal reference gene (Supplemental File 6). Quantitative RT-PCR (qRT-PCR) was performed by an Eppendorf CFX96 ${ }^{\text {TM }}$ Real-Time System (Eppendorf, Germany) using the TransStart Green qPCR SuperMix (TransGen Biotech, BeiJing, China) in accordance with the manufacturer's instructions. The data analysis was based on the 
comparative threshold cycle (Ct) values of the PCR products, and the relative expression levels of the target genes were calculated as $2^{-\Delta \Delta C t}$. All reactions were run in triplicate and the resulting $\mathrm{Ct}$ values were analyzed by a one-way analysis of variance (ANOVA) using the statistical software SPSS 20.0. The results were given in terms of relative mRNA expressed as means \pm standard errors.

\section{Abbreviations}

hpi, hours post infection; RNA-seq, Ribonucleic Acid-sequence; COG, Groups of proteins; GO, Gene Ontology; KEGG, Kyoto Encyclopedia of Genes and Genomes; NR, non-redundant protein sequences; FC, Fold Change; FDR, False discovery rate; DEGs, differentially expressed genes; MyD88, Myeloid differentiation factor 88; Hsp70, Heat shock 70 kDa protein; TLRs, toll-like receptors; PRRs, pattern recognition receptors; FREPs, fibrinogen-like proteins; DAMPs, damage associated molecular patterns; FAO, Food and Agriculture Organization of the United Nations; TRIM, Tripartite motif-containing; PAMPs, pathogen-associated molecular patterns; MAPK, mitogen-activated protein kinases; HSPs, heat shock proteins; CR1L, component receptor 1-like protein; IL17, Interleukin 17; IRAK4, IL-1 receptor-associated kinase 4; TRAF 6, TNF receptor-associated factor 6; NF-KB, nuclear factor-kB; qRT-PCR, Quantitative Realtime PCR; EF1-a, elongation factor 1 a; C1q4, Complement C1q-like protein 4; SPI, Serine protease inhibitor dipetalogastin; AOM, Alternative oxidase, mitochondrial; TRAFP, TNF receptor-associated factor family protein; FC1, Fibrinogen C domain-containing protein 1; LPS, lipopolyssacharide; PGN, peptidoglycan; PGRPs, peptidoglycan recognition proteins; SRs, scavenger receptors; MMR, macrophage mannose receptor; LPS-BP, hemolymph lipopolysaccharide-binding protein ; OsHV-1 mvar, herpesvirus-1 microvariant; HMGB1, high-mobility group box 1; MASPs, MBL-associated serine proteases; TNFa, tumor necrosis factor-a; IFNs, interferons; CSFs, colony-stimulating factors; CFU, Colony-Forming Units; DEPC, diethyl pyrocarbonate; FPKM, fragments per kilobase of transcript

\section{Declarations}

\section{Ethics approval and consent to participate}

The oysters used in this study were marine-cultured animal and were collected from a local farm in Yantai, China. There are no specific permissions required for the sampling of these oysters. All experiments were conducted with approval from the Experimental Animal Ethics Committee, Beibu Gulf University and Zhejiang University, China.

\section{Consent for publication}

Not applicable.

\section{Availability of data and material}

The transcriptome datasets supporting the results of this study are available in the NCBI BioProject repository (Accession Number PRJNA623063) and in the SRA database (https://submit.ncbi.nlm.nih.gov/subs/sra/SUB7232205/overview, SUB7232205). 


\section{Competing interests}

The authors declare that they have no competing interests.

\section{Funding}

This research was financed by National Natural Science Foundation of China (NSFC 31272682).

\section{Authors' contributions}

All authors read and approved the final manuscript. J.F, PC.H and XZ.W wrote the manuscript. HY.L, HL.C, MH.Q and JR.H commented on the manuscript. J.F, FY.M, XH.C performed and supervised the experiments. J.F and XH.C assembled, annotated, and analyzed the transcriptome data. PC.H and XZ.W contributed to the conceptualization.

\section{Acknowledgements}

We gratefully acknowledge financial support of National Natural Science Foundation of China (NO. 31272682) and thank all members of the laboratory for helping to sample the oyster.

\section{References}

1. Huang B, Zhang L, Li L, Tang X, Zhang G. Highly diverse fibrinogen-related proteins in the Pacific oyster Crassostrea gigas. Fish Shellfish Immunol. 2015;43(2):485-90.

2. Paillard C, Le Roux F, Borrego JJ. Bacterial disease in marine bivalves, a review of recent studies: trends and evolution. Aquatic Living Resources. 2004;17(4):477-498.

3. Wang Z,Wang B, Chen G, Jian J, Lu Y, Xu Y, Wu Z. Transcriptome analysis of the pearl oyster ( Pinctada fucata) hemocytes in response to Vibrio alginolyticus infection. Gene. 2016;575(2): 421428.

4. Dyrynda EA, Pipe RK, Ratcliffe NA. Host defence mechanisms in marine invertebrate larvae. Fish Shellfish Immunol. 1995;5(8): 569-580.

5. Song X, Wang H, Xin L, Xu J, Jia Z, Wang L, Song L. The immunological capacity in the larvae of Pacific oyster Crassostrea gigas. Fish Shellfish Immunoly. 2016;49: 461-469.

6. Genard B, Miner P, Nicolas JL, Moraga D, Boudry P, Pernet F, Tremblay R. Integrative study of physiological changes associated with bacterial infection in Pacific oyster larvae. PLoS One. 2013;8(5):e64534.

7. Tirapé A, Bacque $C$, Brizard R, Vandenbulcke F, Boulo V. Expression of immune-related genes in the oyster Crassostrea gigas during ontogenesis. Dev Comp Immunol. 2007;31(9):859-873.

8. Fleury E, Huvet A. Microarray analysis highlights immune response of Pacific oysters as a determinant of resistance to summer mortality. Mar Biotechnol (NY). 2012;14(2):203-217. 
9. de Lorgeril J, Zenagui R, Rosa RD, Piquemal D, Bachère E. Whole transcriptome profiling of successful immune response to Vibrio infections in the oyster Crassostrea gigas by digital gene Expression Analysis. PLoS One. 2011;6(8):e23142.

10. Zhang G, Fang X, Guo X, Li L, Luo R, Xu F, Yang P, Zhang L, Wang X, Qi H, et al. The oyster genome reveals stress adaptation and complexity of shell formation. Nature. 2012;490(7418):49-54.

11. Gueguen Y, Cadoret JP, Flament D, Barreau-Roumiguière C, Girardot AL, Garnier J, Hoareau A, Bachère E, Escoubas JM. Immune gene discovery by expressed sequence tags generated from hemocytes of the bacteria-challenged oyster, Crassostrea gigas. Gene. 2003;303:139-145.

12. Liu H, He J, Chi C, Lv Z. Identification and analysis of HSP70 from Sepiella maindroni under stress of Vibrio harveyi and $\mathrm{Cd}^{2+}$. Gene. 2015;572(1):146-152.

13. Fujita T, Endo Y, Nonaka M. Primitive complement system-recognition and activation. Mol Immunol. 2004;41(2-3):103-111.

14. Beutler B. Innate immunity: an overview. Mol Immunol. 2004;40(12):845-859.

15. Schmidt BZ, Colten HR. Complement: a critical test of its biological importance. Immunol Rev. 2000;178:166-176.

16. Guo X, Ford SE. Infectious diseases of marine molluscs and host responses as revealed by genomic tools. Philos Trans R Soc Lond B Biol Sci. 2016;5:371(1689).

17. Mukherjee J, Wong KK, Chandramouli KH, Qian PY, Leung PT, Wu RS, Thiyagarajan V. Proteomic response of marine invertebrate larvae to ocean acidification and hypoxia during metamorphosis and calcification. J Exp Biol. 2013;216(Pt 24):4580-4589.

18. lizuka M, Nagasaki T, Takahashi KG, Osada M, Itoh N. Involvement of Pacific oyster CgPGRP-S1S in bacterial recognition, agglutination and granulocyte degranulation. Dev Comp Immunol. 2014;43(1):30-34.

19. Zhang L, Li L, Zhang G. A Crassostrea gigas Toll-like receptor and comparative analysis of TLR pathway in invertebrates. Fish Shellfish Immunol. 2011;30(2):653-660.

20. Huang B, Zhang L, Li L, Tang X, Zhang G. Highly diverse fibrinogen-related proteins in the Pacific oyster Crassostrea gigas. Fish Shellfish Immunol. 2015;43(2):485-490.

21. Liu L, Yang J, Qiu L, Wang L, Zhang H, Wang M, Vinu SS, Song L. A novel scavenger receptorcysteine-rich (SRCR) domain containing scavenger receptor identified from mollusk mediated PAMP recognition and binding. Dev Comp Immunol. 2011;35(2):227-239.

22. Yu A, Jin K, Guo N, Li S, Wu M, Li W, Wang Q. Two novel Toll genes (EsToll1 and EsToll2) from Eriocheir sinensis are differentially induced by lipopolysaccharide, peptidoglycan and zymosan. Fish Shellfish Immunol. 2013;35(4):1282-1292.

23. Ertl NG, O'Connor WA, Papanicolaou A, Wiegand AN, Elizur A. Transcriptome Analysis of the Sydney Rock Oyster, Saccostrea glomerata: Insights into Molluscan Immunity. PLoS One. 2016;11(6):e0156649. 
24. Liu TY, Minetti CA, Fortes-Dias CL, Liu T, Lin L, Lin Y. C-reactive proteins, limunectin, lipopolysaccharide-binding protein, and coagulin. Molecules with lectin and agglutinin activities from Limulus polyphemus. Ann N Y Acad Sci. 1994;712:146-154.

25. Yang J, Wang W, Wei X, Qiu L, Wang L, Zhang H, Song L. Peptidoglycan recognition protein of Chlamys farreri (CfPGRP-S1) mediates immune defenses against bacterial infection. Dev Comp Immunol. 2010;34(12):1300-1307.

26. Adema CM, Hertel LA, Miller RD, Loker ES. A family of fibrinogen-related proteins that precipitates parasite-derived molecules is produced by an invertebrate after infection. Proc Natl Acad Sci U S A. 1997;94(16):8691-8696.

27. Adema CM. Fibrinogen-Related Proteins (FREPs) in Mollusks. Results Probl Cell Differ. 2015;57:111129.

28. Li H, Hambrook JR, Pila EA, Gharamah AA, Fang J, Wu X, Hanington P. Coordination of humoral immune factors dictates compatibility between Schistosoma mansoni and Biomphalaria glabrata. Elife. 2020;9:e51708.

29. Hertel LA, Adema CM, Loker ES. Differential expression of FREP genes in two strains of Biomphalaria glabrata following exposure to the digenetic trematodes Schistosoma mansoni and Echinostoma paraensei. Dev Comp Immunol. 2005;29(4):295-303.

30. Zhang SM, Zeng Y, Loker ES. Expression Profiling and Binding Properties of Fibrinogen-Related Proteins (FREPs), Plasma Proteins From the Schistosome Snail Host Biomphalaria Glabrata. Innate Immun. 2008;14(3):175-189.

31. Fan C, Zhang S, Li L, Chao Y. Fibrinogen-related protein from amphioxus Branchiostoma belcheri is a multivalent pattern recognition receptor with a bacteriolytic activity. Mol Immunol. 2008;45(12):33383346.

32. Wang X, Rocheleau TA, Fuchs JF, Hillyer JF, Chen CC, Christensen BM. A novel lectin with a fibrinogen-like domain and its potential involvement in the innate immune response of Armigeres subalbatus against bacteria. Insect Mol Biol. 2004;13(3):273-282.

33. Christophides GK, Zdobnov E, Barillas-Mury C, Birney E, Blandin S, Blass C, Brey PT, Collins FH, Danielli A, Dimopoulos G, et al. Immunity-related genes and gene families in Anopheles gambiae. Science. 2002;298(5591):159-165.

34. Dimopoulos G, Christophides GK, Meister S, Schultz J, White KP, Barillas-Mury C, Kafatos FC. Genome expression analysis of Anopheles gambiae: responses to injury, bacterial challenge, and malaria infection. Proc Natl Acad Sci U S A. 2002;99(13):8814-8819.

35. Li H, Zhang H, Jiang S, Wang W, Xin L, Wang H, Wang L, Song L. A single-CRD C-type lectin from oyster Crassostrea gigas mediates immune recognition and pathogen elimination with a potential role in the activation of complement system. Fish Shellfish Immunol. 2015;44(2):566-575.

36. Yang J, Qiu L, Wei X, Wang L, Wang L, Zhou Z, Zhang H, Liu L, Song L. An ancient C-type lectin in Chlamys farreri (CfLec-2) that mediate pathogen recognition and cellular adhesion. Dev Comp Immunol. 2010;34(12):1274-1282. 
37. Weis WI, Taylor ME, Drickamer K. The c-type lectin superfamily in the immune system. Immunol Rev. 1998;163:19-34.

38. Lemaitre B, Nicolas E, Michaut L, Reichhart JM, Hoffmann JA. The dorsoventral regulatory gene cassette spätzle/Toll/cactus controls the potent antifungal response in Drosophila adults. Cell. 1996;86(6):973-983.

39. Wu Y, Liang H, Wang Z, Lei Q, Xia L. A novel toll-like receptor from the pearl oyster Pinctada fucata martensii is induced in response to stress. Comp Biochem Physiol B Biochem Mol Biol. 2017;214:1926.

40. Ren Q, Lan JF, Zhong X, Song XJ, Ma F, Hui KM, Wang W, Yu XQ, Wang JX. A novel Toll like receptor with two TIR domains (HcToll-2) is involved in regulation of antimicrobial peptide gene expression of Hyriopsis cumingii. Dev Comp Immunol. 2014;45(1):198-208.

41. Wang W, Zhang T, Wang L, Xu J, Li M, Zhang A, Qiu L, Song L. A new non-phagocytic TLR6 with broad recognition ligands from Pacific oyster Crassostrea gigas. Dev Comp Immunol. 2016;65:182190.

42. Zhou SM, Yuan XM, Liu S, Li M, Tao Z, Wang GL. Three novel Toll genes (PtToll1e3) identified from a marine crab, Portunus trituberculatus. Different tissue expression and response to pathogens. Fish Shellfish Immunol. 2015;46(2):737-744.

43. Yu AQ, Jin XK, Guo XN, Li S, Wu MH, Li WW, Wang Q. Two novel Toll genes (EsToll1 and EsToll2) from Eriocheir sinensis are differentially induced by lipopolysaccharide, peptidoglycan and zymosan. Fish Shellfish Immunol. 2013;35(4):1282-1292.

44. Baoyu Huang, Linlin Zhang, Fei Xu, Xueying Tang, Li Li, Wei Wang, Mingkun Liu, Guofan Zhang. Oyster Versatile IKKa/ $\beta$ s Are Involved in Toll-Like Receptor and RIG-I-Like Receptor Signaling for Innate Immune Response. Front Immunol. 2019;10:1826.

45. Yang Zhang, Xiaocui He, Feng Yu, Zhiming Xiang, Jun Li, Karen L Thorpe, Ziniu Yu. Characteristic and Functional Analysis of Toll-Like Receptors (TLRs) in the Lophotrocozoan, Crassostrea Gigas, Reveals Ancient Origin of TLR-mediated Innate Immunity. PLoS One. 2013;8 (10):e76464

46. Jiao Y, Gu Z, Luo S, Deng Y. Evolutionary and functional analysis of MyD88 genes in pearl oyster Pinctada fucata martensii. Fish Shellfish Immunol. 2020;99:322-330.

47. Wang M, Yang J, Zhou Z, Qiu L, Wang L, Zhang H, Gao Y, Wang X, Zhang L, Zhao J, Song L. A primitive Toll-like receptor signaling pathway in mollusk Zhikong scallop Chlamys farreri. Dev Comp Immunol. 2011;35(4):511-520.

48. Tang X, Huang B, Zhang L, Li L3, Zhang G. Molecular characterization of Pacific oyster (Crassostrea gigas) IRAK4 gene and its role in MyD88-dependent pathway. Dev Comp Immunol. 2017;72:21-29.

49. Scaffidi P, Misteli T, Bianchi ME. Release of chromatin protein HMGB1 by necrotic cells triggers inflammation. Nature. 2002;418(6894):191-195.

50. Li J, Zhang Y, Liu Y, Zhang Y, Xiao S, Yu Z. Co-expression of heat shock protein (HSP) 40 and HSP70 in Pinctada martensii response to thermal, low salinity and bacterial challenges. Fish Shellfish Immunol. 2016;48:239-243. 
51. Srivastava P. Roles of heat-shock proteins in innate and adaptive immunity. Nat Rev Immunol. 2002;2(3):185-194.

52. Feder ME, Hofmann GE. Heat-shock proteins, molecular chaperones, and the stress response: evolutionary and ecological physiology. Annu Rev Physiol. 1999;61:243-282.

53. Cellura C, Toubiana M, Parrinello N, Roch P. HSP70 gene expression in Mytilus galloprovincialis hemocytes is triggered by moderate heat shock and Vibrio anguillarum, but not by $\mathrm{V}$. splendidus or Micrococcus lysodeikticus. Dev Comp Immunol. 2006;30(11):984-997.

54. Park H, Ahn IY, Lee HE. Expression of heat shock protein 70 in the thermally stressed Antarctic clam Laternula elliptica. Cell Stress Chaperones. 2007;12:275-282.

55. Liu H, He J, Chi C, Shao J. Differential HSP70 expression in Mytilus coruscus under various stressors. Gene. 2014;543(1):166-173.

56. Wang Z, Wu Z, Jian J, Lu Y. Cloning and expression of heat shock protein 70 gene in the haemocytes of pearl oyster (Pinctada fucata, Gould 1850) responding to bacterial challenge. Fish Shellfish Immunol. 2009;26(4):639-645.

57. Carroll MC. The complement system in regulation of adaptive immunity. Nat Immunol. 2004;5(10):981-986.

58. Nonaka M, Yoshizaki F. Evolution of the complement system. Mol Immunol. 2004;40(12): 897-902.

59. Kishore U, Gaboriaud C, Waters P, Shrive AK, Greenhough TJ, Reid KB, Sim RB, Arlaud GJ. C1q and tumor necrosis factor superfamily : modularity and versatility. Trends Immunol. 2004;25(10):551561.

60. Smith LC, Chang L, Britten RJ, Davidson EH. Sea urchin genes expressed in activated coelomocytes are identified by expressed sequence tags. J Immunol. 1996;156(2):593-602.

61. Paulchamy R, Sreeramulu B, Karuppiah H, Arumugam G, Sundaram J. A serine protease-associated lectin in the cytolytic system of blowfly (Chrysomya megacephala) larvae: Evidence and characterization. Arch Insect Biochem Physiol. 2019;e21623.

62. Cerenius L, Söderhäll K. Arthropoda: Pattern recognition proteins in crustacean immunity. advances in comparative immunology. Springer, Cham. 2018;213-224.

63. Chen $D$, Yao $Y$, Zhang $Y$. Identification and characterization of two mannan-binding lectin associated proteins in lectin complement pathway of grass carp. Dev Comp Immunol. 2019;103:103497.

64. Gorbushin AM. Immune repertoire in the transcriptome of Littorina littorea reveals new trends in lophotrochozoan proto-complement evolution. Dev Comp Immunol. 2018;84:250-263.

65. Cui Y, Wei Z, Shen Y, Li C, Shao Y, Zhang W, Zhao X. A Novel C1q-domain-containing Protein From Razor Clam Sinonovacula Constricta Mediates G-bacterial Agglutination as a Pattern Recognition Receptor. Dev Comp Immunol. 2018;79:166-174.

66. Xu T, Xie J, Li J, Luo M, Ye S, Wu X. Identification of expressed genes in cDNA library of hemocytes from the RLO-challenged oyster, Crassostrea Ariakensis Gould with special functional implication of 
three complement-related fragments (CaC1q1, CaC1q2 and CaC3). Fish Shellfish Immunol. 2012;32 (6): 1106-1116.

67. Kimura A, Sakaguchi E, Nonaka M. Multi-component complement system of Cnidaria: C3, Bf, and MASP genes expressed in the endodermal tissues of a sea anemone, Nematostella vectensis. Immunobiology. 2009;214(3):165-178.

68. Gerdol M, Manfrin C, De MG, Figueras A, Novoa B, Venier P, Pallavicini. The C1q domain containing proteins of the Mediterranean mussel Mytilus galloprovincialis. a widespread and diverse family of immune-related molecules. Dev Comp Immunol. 2011;35:635.

69. Gestal C, Pallavicini A, Venier P, Novoa B, Figueras A. MgC1q, a novel C1q-domain-containing protein involved in the immune response of Mytilus galloprovincialis. Dev Comp Immunol. 2010;34:926-934.

70. Bathige SDNK, Umasuthan N, Jayasinghe JDHE, Godahewa GI, Park HC, Lee J. Three novel C1q domain containing proteins from the disk abalone Haliotis discus discus. genomic organization and analysis of the transcriptional changes in response to bacterial pathogens. Fish Shellfish Immunol. 2016;56:181-187.

71. Liu N, Pan L, Gong X, Tao Y, Hu Y, Miao J. Effects of benzo(a)pyrene on differentially expressed genes and haemocyte parameters of the clam Venerupis philippinarum. Ecotoxicology. 2014;23(2):122-132.

72. Song Y, Guo Q, Gao S, Hua K. Tripartite motif-containing protein 3 plays a role of tumor inhibitor in cervical cancer. Biochem Biophys Res Commun. 2018;498(3):686-692.

73. Craig A, Ewan R, Mesmar J, Gudipati V, Sadanandom A. E3 ubiquitin ligases and plant innate immunity. J Exp Bot. 2009;60(4): 1123-1132.

74. Rossi M, De Laurenzi V, Munarriz E, Green DR, Liu YC, Vousden KH, Cesareni G, Melino G. The ubiquitineprotein ligase Itch regulates p73 stability. EMBO J. 2005;24(4):836-848.

75. Nabika T, Terashima M, Momose I, Hosokawad Y, Nagasuea N, Tanigawa Y. Synergistic effect of ubiquitin on lipopolysaccharide-induced TNF-a production in murine macrophage cell line RAW 264.7 cells. Biochimica et Biophysica Acta (BBA)-Molecular Cell Research. 1999;1450(1): 25-34.

76. Hatakeyama S. TRIM Family Proteins: Roles in Autophagy, Immunity, and Carcinogenesis. Trends Biochem Sci. 2017;42(4):297-311.

77. Sawyer SL, Emerman M, Malik HS. Discordant evolution of the adjacent antiretroviral genes TRIM22 and TRIM5 in mammals. PLoS Pathog. 2007;3(12):e197.

78. Reymond A, Meroni G, Fantozzi A, Merla G, Cairo S, Luzi L, Riganelli D, Zanaria E, Messali S, Cainarca S, et al. The tripartite motif family identifies cell compartments. EMBO J. 2001;20(9):2140-2151.

79. Rajsbaum R, Stoye JP, O'Garra A. Type I interferon-dependent and -independent expression of tripartite motif proteins in immune cells. Eur J Immunol. 2008;38(3):619-630.

80. Uchil PD, Hinz A, Siegel S, Coenen-Stass A, Pertel T, Luban J, Mothes W. TRIM protein-mediated regulation of inflammatory and innate immune signaling and its association with antiretroviral activity. J Virol. 2013;87(1):257-272. 
81. Kawai T, Akira S. Regulation of innate immune signalling pathways by the tripartite motif (TRIM) family proteins. EMBO Mol Med. 2011;3(9):513-527.

82. Rosani U, Varotto L, Domeneghetti S, Arcangeli G, Pallavicini A, Venier P. Dual analysis of host and pathogen transcriptomes in ostreid herpesvirus 1-positive Crassostrea gigas. Environ Microbiol. 2015;17(11):4200-4212.

83. Song $Y$, Guo Q, Gao S, Hua K. Tripartite motif-containing protein 3 plays a role of tumor inhibitor in cervical cancer. Biochem Biophys Res Commun. 2018;498(3):686-692.

84. Cheng Q, Wang H, Jiang S, Wang L, Xin L, Liu C, Jia Z, Song L, Zhu B. Qiu. Dev Comp Immunol. 2016;60:180-190.

85. Seo JK, Lee MJ, Go HJ, Kim GD, Jeong HD, Nam BH, Park NG. Purification and antimicrobial function of ubiquitin isolated from the gill of Pacific oyster, Crassostrea gigas. Mol Immunol. 2013;53(1-2):8898.

86. Wu L, Wu X, Wang L. Identification and functional characterization of an Rbx1 in an invertebrate Haliotis diversicolor supertexta. Dev Comp Immunol. 2011;35(1):72-80.

87. Li J, Zhang Y, Zhang Y, Xiang Z, Tong Y, Qu F, Yu Z. Genomic Characterization and Expression Analysis of Five Novel IL-17 Genes in the Pacific Oyster, Crassostrea Gigas. Fish Shellfish Immunol.2014;40 (2):455-465.

88. Rouvier E, Luciani MF, Mattéi MG, Denizot F, Golstein P. CTLA-8, cloned from an activated T cell, bearing AU-rich messenger RNA instability sequences, and homologous to a herpesvirus saimiri gene. J Immunol. 1993;150(12):5445-5456.

89. Vizzini A, Di Falco F, Parrinello D, Sanfratello MA, Mazzarella C, Parrinello N1, Cammarata M. Ciona intestinalis interleukin 17-like genes expression is upregulated by LPS challenge. Dev Comp Immunol. 2015;48(1):129-137.

90. Jin W, Dong C. IL-17 cytokines in immunity and inflammation. Emerg Microbes Infect. 2013;2(9): e60.

91. Liu W, Huang X, Wang Q, Zhao M, Wu S, He M. Gene cloning and function analysis of cytokineinduced suppressor of cytokine signaling (SOCS) from pearl oyster Pinctada fucata. Fish Shellfish Immunol. 2013;34(3):849-854.

92. Zhang R, Wang M, Xia N, Yu S, Chen Y, Wang N. Cloning and analysis of gene expression of interleukin-17 homolog in triangle-shell pearl mussel, Hyriopsis cumingii, during pearl sacformation. Fish Shellfish Immunol. 2016;52:151-156.

93. Wu S, Huang X, Li Q, He M. Interleukin-17 in pearl oyster (Pinctada Fucata): molecular cloning and functional characterization. Fish Shellfish Immunol. 2013;34 (5):1050-1056.

94. Roberts S, Gueguen Y, de Lorgeril J, Goetz F. Rapid accumulation of an interleukin 17 homolog transcript in Crassostrea gigas hemocytes following bacterial exposure. Dev Comp Immunol. 2008;32(9):1099-1104.

95. Wu S, Huang X, Li Q, He M. Interleukin-17 in pearl oyster (Pinctada fucata): Molecular cloning and functional characterization. Fish Shellfish Immunol. 2013;34(5):1050-1056. 
96. Kim D, Pertea G, Trapnell C, Pimentel H, Kelley R, Salzberg SL. TopHat2: accurate alignment of transcriptomes in the presence of insertions, deletions and gene fusions. Genome Biol. 2013;14(4):R36.

97. Trapnell C, Williams BA, Pertea G, Mortazavi A, Kwan G, van Baren MJ, Salzberg SL, Wold BJ, Pachter L. Transcript assembly and quantification by RNA Seq reveals unannotated transcripts and isoform switching during cell differentiation. Nat Biotechnol. 2010;28(5):511-515.

98. Anders S, Huber W. Differential expression analysis for sequence count data. Genome Biol. 2010;11(10):R106.

\section{Additional Files}

Additional file 1 (xls.): Total DEGs between the experimental and control group at $6 \mathrm{~h}, 12 \mathrm{~h}, 24 \mathrm{~h}, 48 \mathrm{~h}$ and 72h after bacterial infection. The file includes following datasheets: Sheet 1. Total DEGs of the oyster larvae post bacteria challenge after $6 \mathrm{~h}$. Sheet 2 . Total DEGs of the oyster larvae post bacteria challenge after $12 \mathrm{~h}$. Sheet 3. Total DEGs of the oyster larvae post bacteria challenge after 24h. Sheet 4. Total DEGs of the oyster larvae post bacteria challenge after $48 \mathrm{~h}$. Sheet 5 . Total DEGs of the oyster larvae post bacteria challenge after $72 \mathrm{~h}$.

Additional file 2 (xls.): GO Functional annotation and classification of DEGs at $6 \mathrm{~h}, 12 \mathrm{~h}, 24 \mathrm{~h}, 48 \mathrm{~h}$ and $72 \mathrm{~h}$ after bacterial infection. The file includes following datasheets: Sheet 1. GO Functional annotation and classification of DEGs at 6h after bacteria infection. Sheet 2. GO Functional annotation and classification of DEGs at 12h after bacteria infection. Sheet 3. GO Functional annotation and classification of DEGs at 24h after bacteria infection. Sheet 4. GO Functional annotation and classification of DEGs at 48h after bacteria infection. Sheet 5. GO Functional annotation and classification of DEGs at 72h after bacteria infection.

Additional file 3 (xls.): KEGG pathway analysis at $6 \mathrm{~h}, 12 \mathrm{~h}, 24 \mathrm{~h}, 48 \mathrm{~h}$ and $72 \mathrm{~h}$ after bacterial infection. The file includes following datasheets: Sheet 1. KEGG pathway at $6 \mathrm{~h}$ post bacteria infection. Sheet 2. KEGG pathway at $12 \mathrm{~h}$ post bacteria infection. Sheet 3. KEGG pathway at $24 \mathrm{~h}$ post bacteria infection. Sheet 4. KEGG pathway at $48 \mathrm{~h}$ post bacteria infection. Sheet 5. KEGG pathway at $72 \mathrm{~h}$ post bacteria infection.

Additional file 4 (xls.): According to the analysis of GO terms and KEGG pathways, we selected the upregulated immune-related genes with a strict threshold criterion ( $\log _{2} F C \geq 1.5$ and FDR<0.01) at $6 \mathrm{~h}, 12 \mathrm{~h}$, $24 \mathrm{~h}, 48 \mathrm{~h}$ and $72 \mathrm{~h}$ after bacterial infection. The file includes following datasheets: Sheet 1 . The upregulated immune-related genes with a strict threshold criterion ( $\log _{2} \mathrm{FC} \geq 1.5$ and FDR<0.01) at $6 \mathrm{~h}$ after bacteria challenge. Sheet 2 . The up-regulated immune-related genes with a strict threshold criterion $\left(\log _{2} \mathrm{FC} \geq 1.5\right.$ and $\left.F D R<0.01\right)$ at $12 \mathrm{~h}$ after bacteria challenge. Sheet 3 . The up-regulated immune-related genes with a strict threshold criterion $\left(\log _{2} \mathrm{FC} \geq 1.5\right.$ and $\left.\mathrm{FDR}<0.01\right)$ at $24 \mathrm{~h}$ after bacteria challenge. Sheet 4. The up-regulated immune-related genes with a strict threshold criterion $\left(\log _{2} \mathrm{FC} \geq 1.5\right.$ and $\left.F D R<0.01\right)$ at 
48h after bacteria challenge. Sheet 5. The up-regulated immune-related genes with a strict threshold criterion $\left(\log _{2} \mathrm{FC} \geq 1.5\right.$ and $\left.\mathrm{FDR}<0.01\right)$ at $72 \mathrm{~h}$ after bacteria challenge.

Additional file 5 (Microsoft Word): Categories based on function during an immune response over the first 72 hours of infection. The file includes following datasheets: Table S1: PRRs gene expression over the first 72 hours of infection. Table S2: TLRs gene expression over the first 72 hours of infection. Table S3: DAMPs gene expression over the first 72 hours of infection. Table S4: Complement gene expression over the first 72 hours of infection. Table S5: TRIM gene expression over the first 72 hours of infection. Table S6: Cytokines gene expression over the first 72 hours of infection. Table S7: Immune signaling pathway gene expression over the first 72 hours of infection. Table S8: Immune effector gene expression over the first 72 hours of infection.

Additional file 6 (xls.): Ten representative genes and the internal reference gene primers.

\section{Figures}




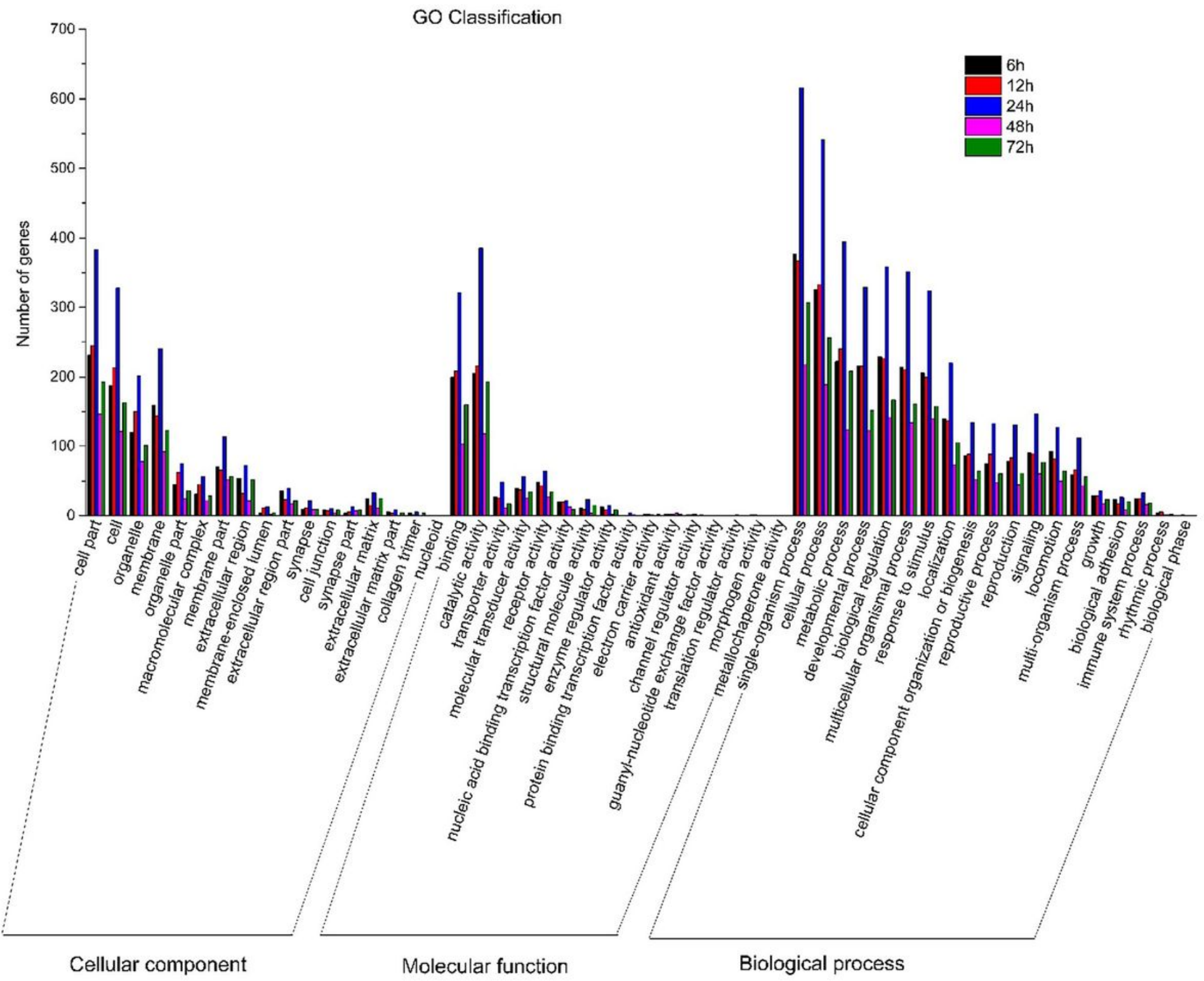

Figure 1

GO classifications of the DEGs. All of the DEGs were assigned to three categories: cellular component, molecular function, and biological process. Note: $6,12,24,48,72 \mathrm{~h}$ means the DEGs from comparison the experiment group with control in $6-72 \mathrm{~h}$ post infection. 


\section{Statistic of Pathway Enrichment Comparing}

\section{the challenged group to the control}

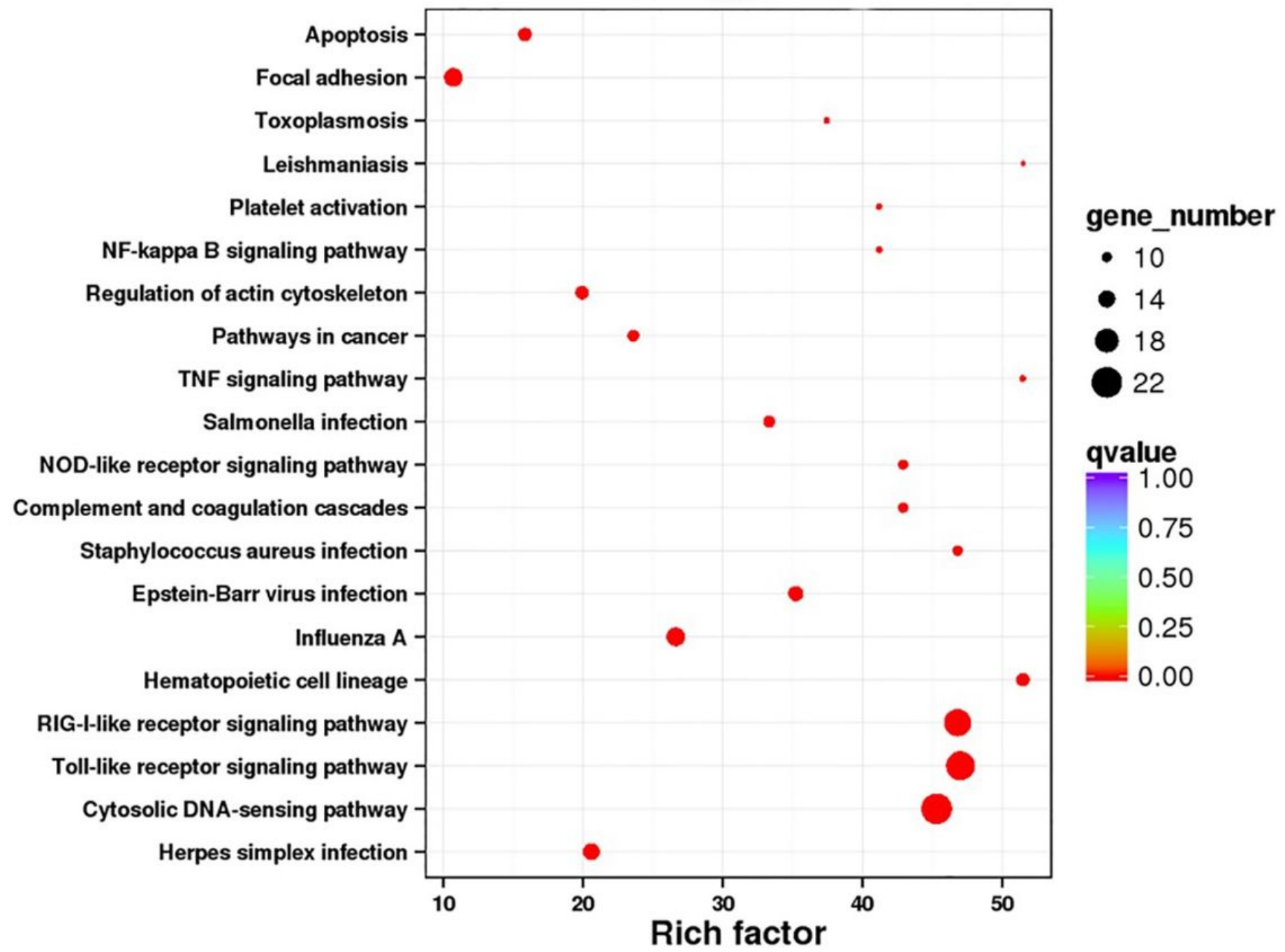

Figure 2

Transcriptomic analysis of the experiment group with control in 6 - $72 \mathrm{~h}$ post infections. Pathway enrichment of the differentially expressed genes was analyzed by the pathway enrichment statistical scatter plot (top 20). 


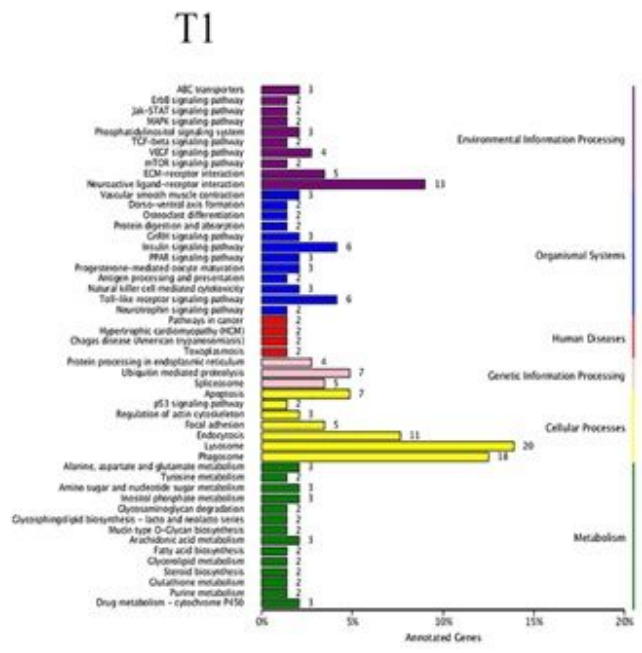

$\mathrm{T} 3$

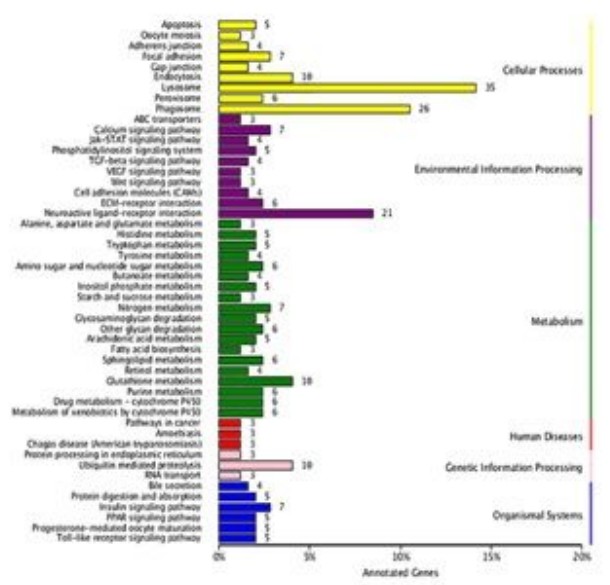

$\mathrm{T} 2$

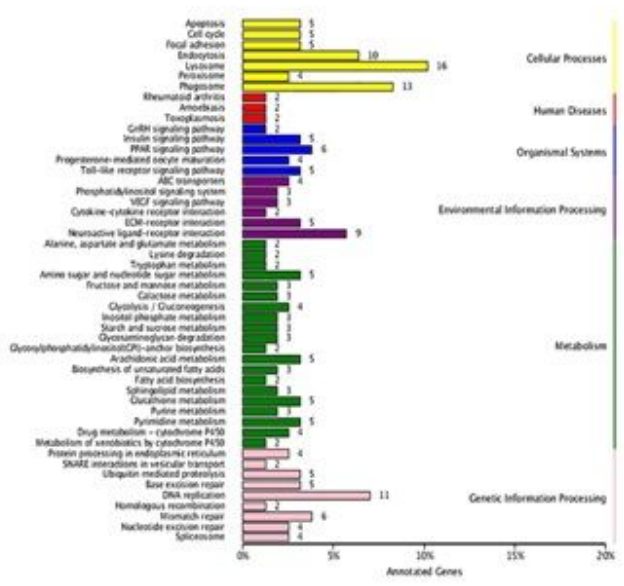

T4

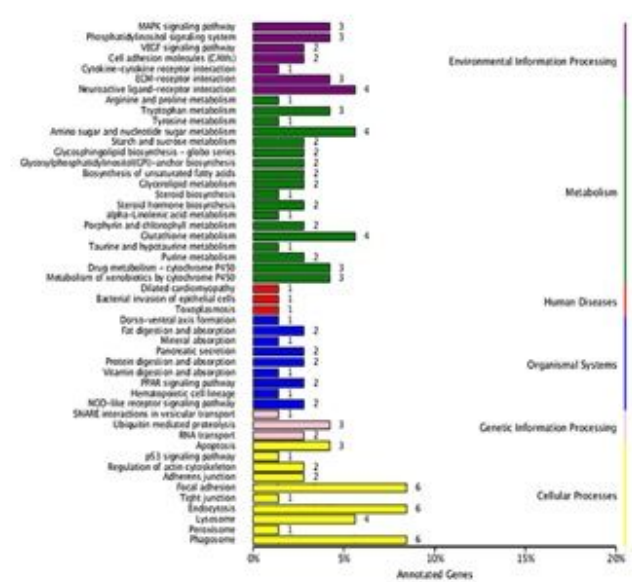

T5

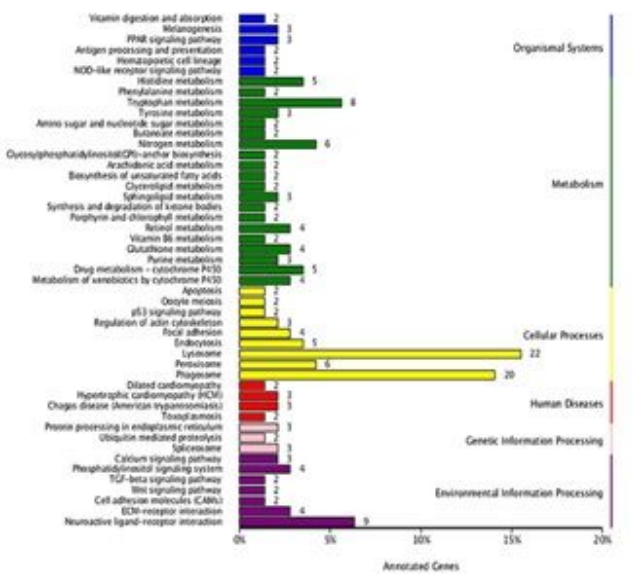

\section{Figure 3}

KEGG classification of DEGs from comparison the experiment group with control in $6-72 \mathrm{~h}$ post infection. Note: T1, T2, T3, T4 and T5 means 6, 12, 24, 48, $72 \mathrm{~h}$ post bacteria challenge. 


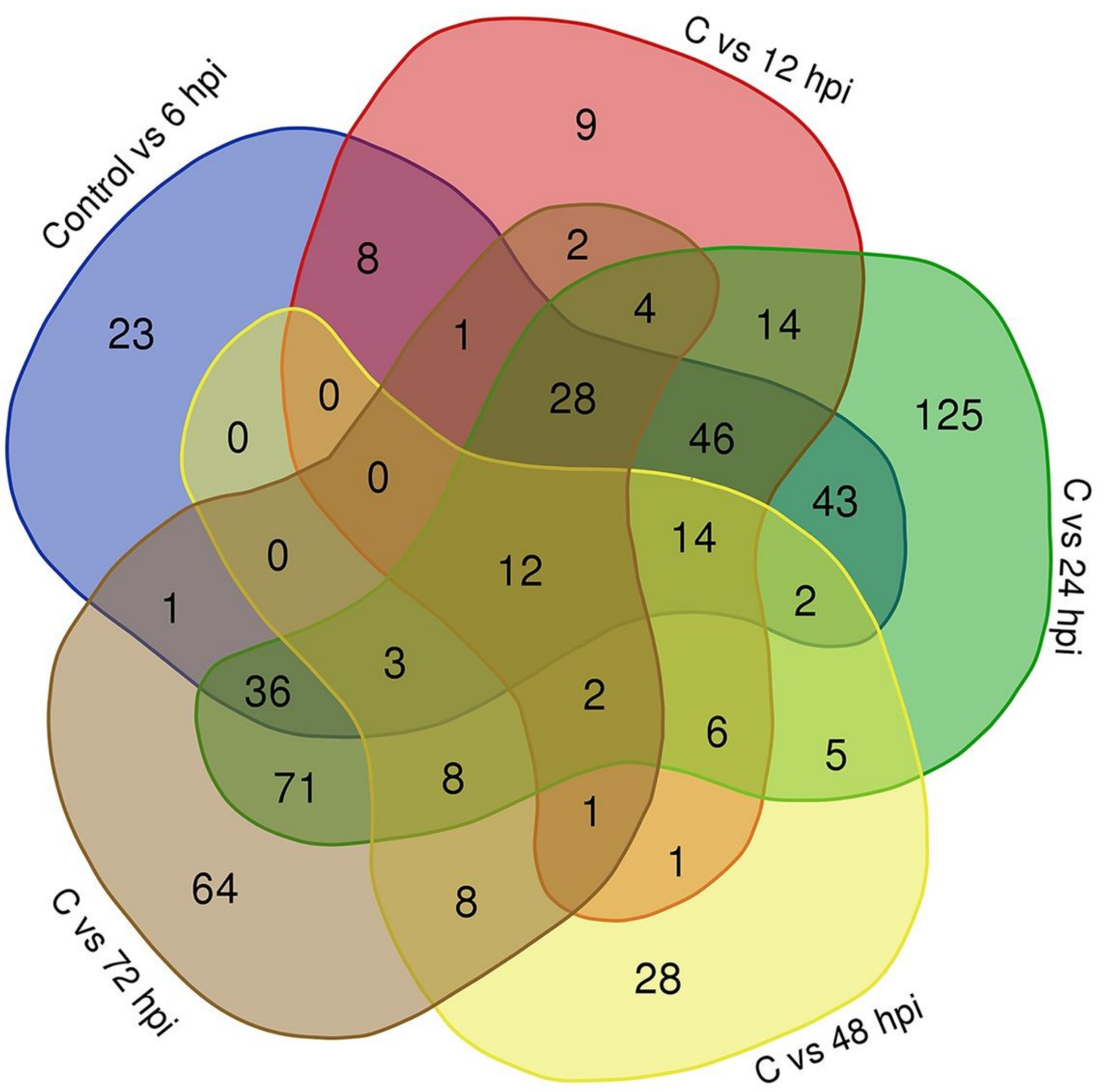

Figure 4

Venn diagram of up-regulated expressed immune-related genes. 

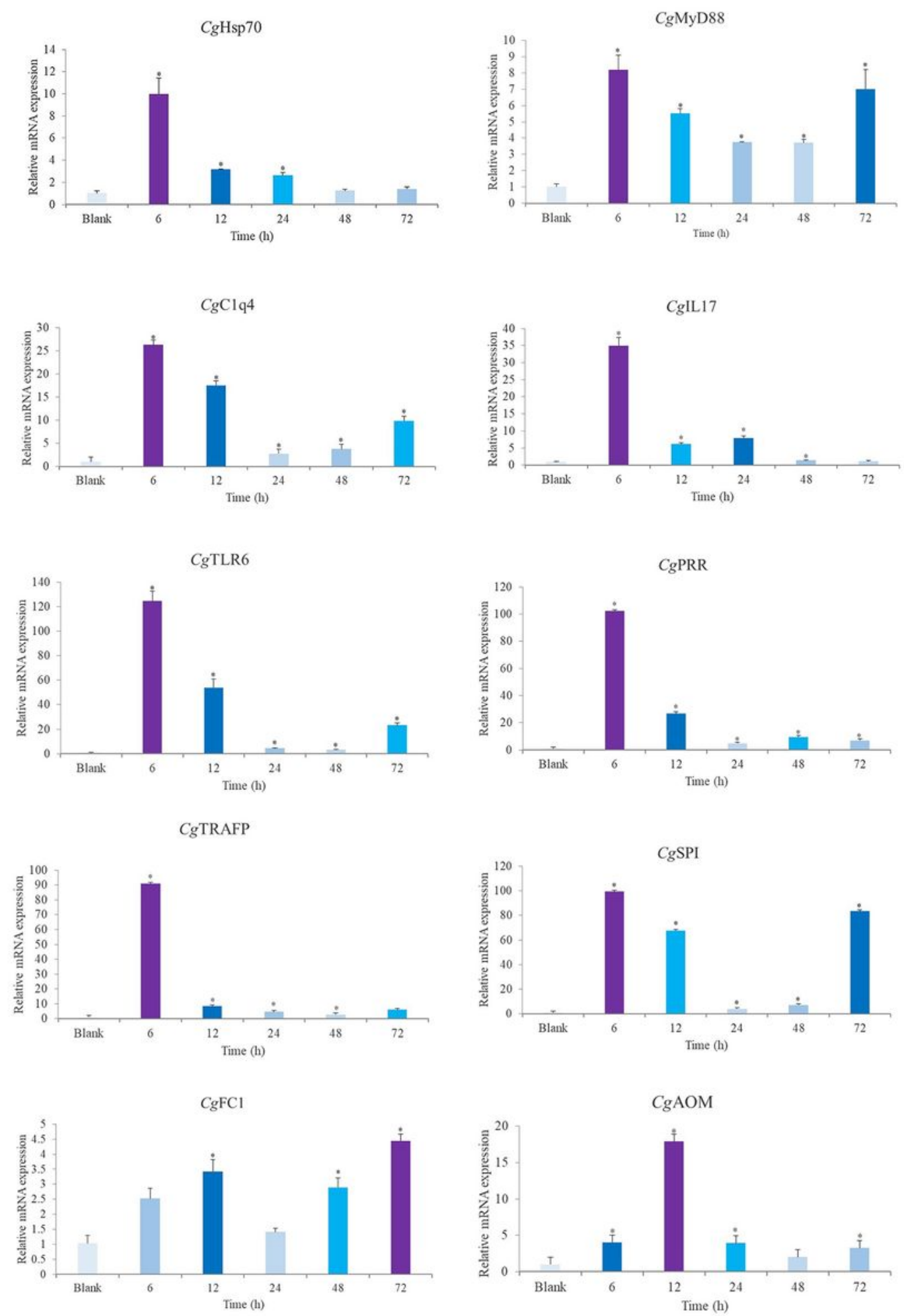

\section{Figure 5}

The relative mRNA expression pattern of ten representative up-regulation immune-related DEGs after bacterial challenge were detected by qRT-PCR at $6 \mathrm{~h}, 12 \mathrm{~h}, 24 \mathrm{~h}, 48 \mathrm{~h}$ and $72 \mathrm{~h}$. The values are given in terms of relative mRNA expressed as mean \pm S.E. $(N=5)$.

\section{Supplementary Files}


This is a list of supplementary files associated with this preprint. Click to download.

- Additionalfile5.doc

- Additionalfile4.xlsx

- Additionalfile1.xlsx

- Additionalfile2.xlsx

- Additionalfile6.xls

- Additionalfile3.xls 